\title{
DESEMPENHO DE LINHAGENS DE AMENDOIM NA REGIÃO DO CERRADO
}

Taís de Moraes Falleiro Suassuna ${ }^{1}$; Jair Heuert ${ }^{1}$; Júlio Cesar Boggiani ${ }^{2}$; Fabiano José Perina ${ }^{2}$; Valdinei Sofiatti ${ }^{3}$; Paulo César Bettini ${ }^{4}$; Murilo Caio Teodoro de Oliveira ${ }^{4}$; Cristian Luarte Leonel ${ }^{5}$

${ }^{1}$ Embrapa Algodão/Núcleo Cerrado, Santo Antônio de Goiás-GO, tais.suassuna@embrapa.br; jair.heuert@embrapa.br; ${ }^{2}$ Embrapa Algodão/Núcleo Cerrado, Luís Eduardo Magalhães-BA; ${ }^{3}$ Embrapa Algodão/Núcleo Cerrado, Palmas-TO; ${ }^{4}$ Terra Pesquisa e Treinamento Agrícola, Primavera do Leste-MT; ${ }^{5}$ Desenvolvimento Técnico de Mercado - BASF, Primavera do Leste-MT.

RESUMO: O amendoim é uma cultura importante para diversificação da produção e de mercados, contribuindo para a sustentabilidade do agronegócio, especialmente na região Sudeste. A região compreendida pelo bioma Cerrado tem sido a região de expansão da produção para as principais commodities brasileiras e pode ser uma região de expansão da cultura do amendoim no Brasil. O desenvolvimento de cultivares tipo "Runner" adaptadas às condições de cultivo no Cerrado é um dos objetivos do Programa de Melhoramento do amendoim da Embrapa. Foram conduzidos quatro ensaios durante a safra 2017-18, em Luís Eduardo Magalhães, BA, em Palmas, TO e dois em Primavera do Leste, MT, visando avaliar o desempenho de linhagens selecionadas pela Embrapa para esta região. Os experimentos foram conduzidos em delineamento em blocos casualizados com quatro repetições e quatro tratamentos (uma cultivar e três linhagens). O manejo da adubação e pragas foi realizado conforme as práticas recomendadas para a cultura. Os ensaios foram colhidos aos 130 dias após a emergência, para avaliação da produtividade e os dados foram avaliados por modelos mistos (REML/BLUP). O genótipo mais produtivo em média nos quatro ensaios foi à linhagem 13-413 OL $\left(6.258,8 \mathrm{~kg} \mathrm{em} \mathrm{casca} \mathrm{por} \mathrm{ha}{ }^{-1}\right)$. O local com a maior média foi Luís Eduardo Magalhães, BA (7.290,2 $\mathrm{kg}$ em casca por ha $\left.{ }^{-1}\right)$.

Palavras-Chave: Arachis hypogaea L., melhoramento genético, cultivares.

\section{INTRODUÇÃO}

A produção brasileira de grãos ocupou uma área de 61,38 milhões de hectares, na safra 2017/18 (CONAB, 2018). Três culturas de verão e uma de inverno ocuparam 89,7 \% desta área: soja (56\%), milho (29\%) e algodão (1,5\%) e trigo (3,2\%). O valor bruto da produção destas commodites foi estimado em R $\$ 188,84$ bilhões.

O restante da área agrícola é cultivado com diversas culturas, dentre as quais oleaginosas como o amendoim. O amendoim é cultivado principalmente nas regiões da Alta Mogiana e Alta Paulista, no estado de São Paulo (SAMPAIO, 2016). A produção é destinada tanto para o mercado interno quanto externo de grãos de alta qualidade, que preferem cultivares alto oleico com ciclo precoce (125 dias) ou médio (140 dias). A estimativa do valor bruto da produção de amendoim em 2017 foi de R\$1,33 bilhões. 
Nas áreas agrícolas do Cerrado, o amendoim é cultivado em sistemas de rotação com outras culturas anuais, além de áreas de renovação de canavial e pastagens. O programa de melhoramento de amendoim para o Cerrado brasileiro teve início em 2010, tendo como uma das fontes de variabilidade cultivares comerciais alto oleico, germoplasma precoce e linhagens interespecíficas (SUASSUNA et al., 2015). Por meio dos métodos convencionais de melhoramento foram selecionados genótipos visando atender às principais demandas dos produtores de amendoim no Brasil: produtividade, tamanho de grão, precocidade, resistência às cercosporioses e alto teor de ácido oleico.

Este trabalho avaliou o desempenho de linhagens de amendoim tipo "Runner" alto oleico, desenvolvidas pelo Programa de Melhoramento do Amendoim da Embrapa, na região Centro-Oeste. Os dados foram analisados via modelos mistos (REML BLUP), visando avaliar o desempenho das linhagens, além de parâmetros de acurácia e precisão dos ensaios, como recomendado por RESENDE \& DUARTE (2007).

\section{MATERIAL E MÉTODOS}

Os experimentos foram conduzidos na área experimental da Fundação Bahia (Luís Eduardo Magalhães, BA), na área da Embrapa Pesca e Aquicultura (Palmas, TO) e em dois locais em Primavera do Leste, MT (MT1 - plantio em 08/12/2017, instalado Estação Experimental da Basf e MT2 - plantio em 28/12/2017, na Estação Experimental da Terra Pesquisa). Foram avaliadas três linhagens avançadas (13-374 OL, 13-413 OL, 13-425 OL) e uma cultivar comercial (IAC OL3). Os tratamentos foram dispostos em delineamento em blocos casualizados, com quatro repetições. As parcelas foram formadas por duas linhas de três metros de comprimento, 0,9 m entre linhas e 17 plantas por metro linear. O manejo da área seguiu as recomendações de cultivo para a cultura, como correção do solo, aplicação de gesso e de fertilizantes de acordo com a análise de solo, manejo de pragas e doenças.

$\mathrm{O}$ arranquio manual das parcelas de cada ensaio foi realizado aos 130 DAE. As parcelas foram mantidas invertidas por 5 dias para completar o processo de cura. O despencamento de cada parcela foi realizado manualmente, seguido de pesagem para estimar a produtividade. Os dados foram analisados via modelos mistos (REML BLUP), utilizando o software Selegen, como descrito por RESENDE \& DUARTE (2007).

\section{RESULTADOS E DISCUSSÃO}

Houve desempenho semelhante entre as linhagens e a cultivar em cada local avaliado, com mudanças no ordenamento das médias de cada tratamento para produtividade. A média geral dos ensaios nos quatro locais foi $6.073,4 \mathrm{~kg}_{\text {por }} \mathrm{ha}^{-1} \mathrm{em}$ casca, refletindo as condições edafoclimáticas e de manejo favoráveis para o desenvolvimento da cultura do amendoim durante a condução dos experimentos. 
A maior produtividade foi obtida em Luís Eduardo Magalhães, BA $\left(7.752,7 \mathrm{~kg}\right.$ por ha ${ }^{-1} \mathrm{em}$ casca), observada na linhagem 13-413 OL. Em Palmas, TO, a linhagem 13-425 OL foi mais produtiva (6.593,7 kg por ha ${ }^{-1}$ em casca). Em Primavera do Leste, MT (MT1) a média do ensaio foi 7.083,0 kg por ha ${ }^{-1}$ em casca. Todos os ensaios foram instalados em área de rotação de culturas anuais, de elevada fertilidade, razão pela qual as produtividades registradas para todos os genótipos foram elevadas, demonstrando a adaptação dos genótipos testados para as condições de cultivo no Cerrado.

Tabela 1. Produtividade ( $\mathrm{kg}$ em casca por $\mathrm{ha}^{-1}$ ) de linhagens avançadas de amendoim, colhidas aos 130 DAE, na região Centro-Oeste (safra 2017-18). Os genótipos foram ordenados com base nos valores genotípicos.

\begin{tabular}{cccccc}
\hline $\begin{array}{c}\text { Genótipos/ } \\
\text { Local }\end{array}$ & $\begin{array}{c}\text { Primavera do } \\
\text { Leste (MT1) }\end{array}$ & $\begin{array}{c}\text { Luís Eduardo } \\
\text { Magalhães (BA) }\end{array}$ & Palmas (TO) & $\begin{array}{c}\text { Primavera do } \\
\text { Leste (MT2) }\end{array}$ & Média \\
\hline 13-413 OL & $7.108,3$ & $7.752,7$ & $6.092,7$ & $4.081,4$ & $6.258,8$ \\
13-425 OL & $7.246,2$ & $6.823,9$ & $6.593,7$ & $3.728,2$ & $6.098,0$ \\
IAC OL3 & $7.314,8$ & $7.482,1$ & $5.518,7$ & $3.579,1$ & $5.973,7$ \\
13-374 OL & $6.662,5$ & $7.101,9$ & $5.813,5$ & $4.274,0$ & $5.963,0$ \\
\hline & & & Média & $6.073,4$ \\
& & & & CV (\%) & 13
\end{tabular}

Em Primavera do Leste, MT, local denominado (MT2) a média do ensaio ficou com 3.915,7 $\mathrm{kg}$ por ha ${ }^{-1}$ em casca. As produtividades foram menores, provavelmente devido a semeadura tardia, em 28 dezembro. Na época de enchimento de grãos houve déficit hídrico, devido à redução no regime hídrico a partir do mês de março, típica do clima da região. Portanto, essa época se torna ariscada para alcançar produtividades maiores.

Apesar de terem desempenho semelhante nos locais descritos acima, RIBEIRO et al., (2017) relatou que as linhagens 13-374 OL, 13-413 OL e 13-425 OL produziram acima de $5.000 \mathrm{~kg}$ por ha ${ }^{-1}$ de amendoim em casca no estado de São Paulo. Informações complementares devem ser consideradas ao selecionar ou indicar genótipos para cultivo em determinadas regiões, visando explorar a melhor adaptação a ambientes específicos, bem como, ser recomendada por apresentar maior estabilidade em diversos ambientes.

\section{CONCLUSÃO}

Foram observadas produtividades elevadas em todas as linhagens desenvolvidas pela Embrapa quando avaliadas em três locais estratégicos do Cerrado brasileiro.

A maior produtividade média foi observada na linhagem 13-413 OL, em Luís Eduardo Magalhães, BA; a mesma linhagem também apresentou a maior produtividade considerando a média dos quatro ensaios avaliados. 


\section{AGRADECIMENTOS}

Os autores prestam seus agradecimentos à Embrapa, por meio do projeto de pesquisa "Melhoramento do Amendoim e Gergelim para Competitividade do Agronegócio (SEG 02.12.02.010.001)”.

\section{REFERENCIAS BIBLIOGRÁFICAS}

CONAB. COMPANHIA NACIONAL DE ABASTECIMENTO. Acompanhamento da safra brasileira - Grãos: V. 5 - SAFRA 2017/18- N. 7 - Sétimo levantamento, Brasília: Companhia Nacional de Abastecimento. ABRIL 2018. Disponível em: https://www.conab.gov.br/.../safras/graos/...safra...graos/.../16780 e7a4a52ee1db76ad1a Acesso em: 01 jul. 2018.

RESENDE, M.D.V.; DUARTE, J.B. (2007) Precisão e controle de qualidade em experimentos de avaliação de cultivares. Pesquisa Agropecuária Tropical 37:182-194.

RIBEIRO, R.P.; HEUERT, J.; SUASSUNA, N.D.; SUASSUNA, T.M.F. (2017) Desempenho de linhagens de amendoim sob alta severidade de doenças foliares. Proceedings... XIV Encontro Sobre a Cultura do Amendoim, Jaboticabal.

SAMPAIO, R.M. (2016) Tecnologia e inovação: evolução e demandas na produção paulista de amendoim. Informações Econômicas SP 46: 27-42.

SUASSUNA, T.M.F.; SUASSUNA, N.D.; MORETZSOHN, M.C.; LEAL-BERTIOLI, S.C.M.;

BERTIOLI, D.J.; MEDEIROS; E.P.; (2015) Yield, market quality, and leaf spots partial resistance of interspecific peanut progenies. Crop Breeding and Applied Biotechnology 15: 1175-180. 